\title{
Reviews
}

\section{MOLECULAR BASIS OF THE DWARFISM CHARACTER IN CULTIVATED PLANTS. I. GROWTH DISTORTIONS DUE TO MUTATIONS OF GIBBERELLIN METABOLISM AND SIGNALING} (review)

\section{T.E. BILOVA ${ }^{1}$, D.N. RYABOVA ${ }^{2}$, I.N. ANISIMOVA ${ }^{2}$}

\author{
${ }^{1}$ Saint Petersburg State University, 7-9, Universitetskaya nab., St. Petersburg, 199034 Russia, e-mail bilova.tati- \\ ana@gmail.com; \\ ${ }^{2}$ Federal Research Center the N.I. Vavilov All-Russian Institute of Plant Genetic Resources, Federal Agency of \\ Scientific Organizations, 42-44, ul. Bol'shaya Morskaya, St. Petersburg, 190000 Russia, e-mail rdash@mail.ru, \\ irina_anisimova@inbox.ru \\ Acknowledgements: \\ We are grateful to Dr O.V. Tankelyun, a senior researcher of the Plant Physiology and Biochemistry Department, \\ St. Petersburg State University, for reading the manuscript and helpful comments. \\ Supported by Saint Petersburg State University (project № 1-38-233-14) and Russian Foundation for Basic Re- \\ search (project № 14-04-01-624) \\ Received January 13, 2015 \\ doi: 10.15389 /agrobiology.2016.1.3eng
}

\section{Abstract}

Development of dwarf cereal varieties with improved mechanical stability of stems preventing their lodging led to significantly increased crop productivity in the 1960-1970s. The creation of novel high-yielding cultivars was one of the main purposes of the «Green revolution» aimed at the reorganization of agriculture in developing countries (G.S. Khush, 2001). At the current time the dwarfism character is of widely use in plant breeding. The dwarf varieties are not only resistant to lodging but also have higher nutrients-absorbing potential and often are more tolerant to diseases than traditional cultivars (K.U. Kurkiev et al., 2006). In connection with that the factors that predetermine plant growth have become of increasing scientific interest over recent years. Numerous dwarf cultivars produced during the «Green revolution» possessed mutant genes responsible for metabolism and transmission of gibberellic (GA) signal (M. Ueguchi-Tanaka et al., 2001; T. Sakamoto et al., 2004). GAs are involved in control of many stages of plant development, including seed germination, stem and root elongation (E. Tanimoto, 2012; P. Hedden, V. Sponsel, 2015). However, alternations at different steps of the GA-dependent processes might lead to different results: to plants with reduced height as well as to tall slender plants. Clear understanding the interaction of genetic and molecular mechanisms will facilitate the revealing of key molecular targets the changes in which would result in production of the desired dwarf varieties. The paper considers the ways of gibberellins biosynthesis, deactivation and how pool of active GAs is maintained. Among numerous known GAs, produced by plants, only $\mathrm{GA}_{1}, \mathrm{GA}_{3}, \mathrm{GA}_{4}, \mathrm{GA}_{5}$ and $\mathrm{GA}_{7}$ are physiologically active. $\mathrm{GA}_{20}$-oxidases and $\mathrm{C} 3, \beta$-oxidases (or $\mathrm{C} 3, \beta$-hydroxylases) involved in production of the active gibberellins catalyze final reactions of gibberellin biosynthesis. $\mathrm{C} 2, \beta$-oxidases are main enzymes that can quickly inactivate active GAs by adding a hydroxyl group $(-\mathrm{OH})$ to a GA molecule. Modern concept about GAsignaling is reviewed according to the following established steps: GA receptor GID1; DELLAproteins as the negative regulators in GA signaling; SCF E3-ubiqutin protein ligase and 26S proteasome; transcriptional factors with DNA-binding site; GA-regulated genes. Accumulated up-to-date data consider that in transmission of gibberellic signal a GA molecule initiates DELLA-protein degradation via interaction of GID1-DELLA complex with E3 SCFSLY1/GID2 (T.-P. Sun, 2011). Thus, reduced growth in dwarf cultivars can be associated with defects in biosynthesis of the active GAs or with accumulation of repressors of GA signaling, the DELLA-proteins, while GA-constitutive growth in tall slender forms might be caused by disturbance in GA-deactivation system or lack of the DELLA repressive function (H. Claeys et al., 2014). The paper also considers ways of participation of gibberellin in the complex hormone regulation of plant growth which occurs often via control over the repressive function of DELLA-proteins (P. Achard et al., 2003). A special attention is paid to characteristics of the genes that lead to altering plant growth, the dwarfism or gigantism.

Keywords: dwarfism, restrained growth, gibberellin signal transduction, receptor GID1, DELLA protein, proteolysis. 
Dwarfing genes are known to be widely used in crop breeding. Dwarf plants are compact and resistant to lodging, which makes them suitable for mechanical harvesting. Additionally, they can possess higher nutrient-use efficiency and be more resistant to diseases. Russian scientists have contributed significantly to the involvement of dwarf forms in breeding rye [1], wheat [2-4], sorghum [5], triticale [6], sunflower [7], fruit plants [8], etc.

In 1920 N.I. Vavilov, in his law of homologous series in variation, paid attention to appearance of dwarf forms and giants in genetically unrelated families (Gramineae, Papilionaceae, Urticaceae, Solanaceae, Rosaceae, etc.). These hereditary variations naturally repeated in different taxa were considered as a result of convergence, evolution, parallel variation or mimicry [9]. Subsequently, factors determining plant growth, as well as genetic and molecular mechanisms of the phenomenon, have been the subject of numerous investigations. Different dwarf varieties have been shown to carry mutations in identical genes. Among plant dwarf mutations the most thoroughly studied ones are those of gibberellin biosynthesis and signaling pathways. The Green Revolution, led by Norman Ernest Borlaug, an American breeder, plant pathologist and Nobel laureate [10], was exactly due to dwarf forms actively used in 1940-1970s. The Green Revolution demonstrated new opportunities of involving variations of agronomic genes in breeding for higher crop yields [11].

Currently, a lot of data are accumulated on how the genes involved in gibberellin biosynthesis and signal transduction regulate plant growth, and the factors responsible for the altered growth phenotypes were found. The objective of our review was to systematize these data, to give a scheme of gibberellin involvement in dwarfing plants, and to explain the molecular mechanisms underlying dwarf mutants traditionally used in plant breeding.

Gibberellins (GA; the abbreviation comes from the most known gibberellic acid - GA) are tetracyclic diterpenes capable of inducing a strong elongation of stems [12]. Among the currently found numerous GA produced by plants, only $\mathrm{GA}_{1}, \mathrm{GA}_{3}, \mathrm{GA}_{4}, \mathrm{GA}_{5}$ and $\mathrm{GA}_{7}$ are physiologically active. The active GA can be rapidly inactivated by adding methyl $\left(-\mathrm{CH}_{3}\right)$, hydroxyl $(-\mathrm{OH})$, and other groups to the molecule. GA are involved in many stages of plant development, including seed germination, stem and root growth, meristem formation, flower, fruit and seed development, photomorphogenesis and circadian rhythms. In case of GA biosynthesis disorder and the lack of active GA, development of dwarf plants with dark green leaves is observed, sometimes with abnormalities of flowering, male sterility and a prolonged dormancy of seeds, to induce germination of which it is often necessary to remove the seed coat [13-16].

The plants with altered growth response are divided into GA-sensitive and GA-insensitive mutants (Table).

Growth response in mutant plants deficient in gibberellin biosynthesis, deactivation and signaling

\begin{tabular}{|c|c|c|c|c|c|}
\hline Plant & $\begin{array}{l}\text { Muta- } \\
\text { tion }\end{array}$ & Encoded protein & $\begin{array}{l}\text { Loss of protein function } \\
\text { (structural damage) }\end{array}$ & Phenotype & $\begin{array}{l}\text { Refer- } \\
\text { ence }\end{array}$ \\
\hline \multicolumn{6}{|c|}{ GA biosynthesis } \\
\hline Arabidopsis & gal-3 & CPS (ent-copalyl diphosphate & Blocking GA synthesis & GA-sensitive, dwarf & {$[16]$} \\
\hline Pea & ls & synthase, EC 5.5.1.13) & at ent-copalyl diphosphate & & {$[17]$} \\
\hline Rice & osks & KS (ent-kaurene synthase, & Blocking GA synthesis & GA-sensitive, dwarf & [14] \\
\hline Maize & $d 5$ & EC 4.2.3.19) & at ent-kaurene & & {$[15]$} \\
\hline Rice & $d 35$ & KO (ent-kaurene oxidase, & Blocking GA synthesis & GA-sensitive, dwarf & [13] \\
\hline Pea & Ih & EC 1.14.13.78) & at ent-kaurene acid & & {$[17]$} \\
\hline Arabidopsis & kaol, & KAO (ent-kaurenoic acid & Blocking GA synthesis & GA-sensitive, dwarf & [16] \\
\hline Pea & kao2 & oxidase, EC 1.14.13.79) of & at $\mathrm{GA}_{12}$ aldehyde & & [17] \\
\hline Maize & na & cytR450 88A1 group & & & [18] \\
\hline Barley & $\begin{array}{l}d 3 \\
\operatorname{grd5}\end{array}$ & $\begin{array}{l}\text { (CYP88A1) in cytochrome } \\
\text { P450 family (CYP) }\end{array}$ & & & [19] \\
\hline
\end{tabular}




\begin{tabular}{|c|c|c|c|c|}
\hline Rice & $s d 1$ & $\begin{array}{l}\mathrm{GA}_{20^{-}} \text {oxidase (EC 1.14.11.12) Blocking oxidation of } \mathrm{C}_{20^{-}} \\
\text {gibberellins to } \mathrm{C}_{19^{-}} \text {gibberellins }\end{array}$ & $\begin{array}{r}\text { Table } \\
\text { GA-sensitive, dwarf }\end{array}$ & $\begin{array}{l}\text { continued } \\
\text { [13] }\end{array}$ \\
\hline Rice & $d 18$ & D18 (Dwarf18) and LE (Length) Blocking hydroxylation at C3, $\beta$ & GA-sensitive, dwarf & {$[13,20]$} \\
\hline Pea & le & $\begin{array}{ll}\text { (gibberellin } 3-\beta \text {-oxidase, EC position in gibberellin biosynthe- } \\
1.14 .11 .15 \text {, or } \mathrm{C} 3, \beta \text {-oxidase) }\end{array}$ & & {$[21,22]$} \\
\hline Pea & $\sin$ & $\begin{array}{ll}\text { G A } & \text { d e a c t i v a t i o n } \\
\text { SLN (Slender) (gibberellin } & \text { Blocking hydroxylation at C2, } \beta \\
\text { 2- } \beta \text {-oxidase, EC 1.14.11.13, } & \begin{array}{l}\text { position in gibberellin deactiva- } \\
\text { or C2, } \beta \text {-oxidase) }\end{array} \\
\text { tion }\end{array}$ & $\begin{array}{l}\text { Slender form with } \\
\text { GA-induced growth }\end{array}$ & {$[17,23]$} \\
\hline $\begin{array}{l}\text { Rice, arabi- } \\
\text { dopsis, rape, } \\
\text { soybean }\end{array}$ & $\operatorname{gid} 1-1$ & $\begin{array}{l}\text { G A p e r c e p t i o n } \\
\text { GID1 (Gibberellin Insensitive Replacement of amino acids in } \\
\text { Dwarf } 1 \text {; high homology of the GXSXG motif (lack of } \\
\text { plant carboxyl esterase with } \alpha-\text { GFA-GID1 formation) } \\
\text { and } \beta \text {-hydrolase superfamily) }\end{array}$ & $\begin{array}{l}\text { GA-insensitive, } \\
\text { dwarf }\end{array}$ & $\begin{array}{l}{[20,24,} \\
25]\end{array}$ \\
\hline Rice & $d 1$ & $\begin{array}{l}\text { G } \alpha \text { ( } \alpha \text {-subunit of hetero- } \quad \text { Function in GA-signaling is not } \\
\text { trimeric G-Enzyme, GTPase, defined } \\
\text { EC 3.6.5.1) }\end{array}$ & $\begin{array}{l}\text { Semi-dwarf (growth } \\
\text { response to GA is } \\
\text { weakened) }\end{array}$ & {$[26,27]$} \\
\hline
\end{tabular}

The first group includes mutants (both dwarfs and giants) sensitive to endogenous GA level. In these plants the mutations affect genes encoding enzymes of GA biosynthesis or deactivation. Therefore, dwarf plant growth can be stimulated by treatment with active GA, and giant plants growth can be slowed down by GA biosynthesis inhibitors. In plants of the second group the growth changes may be associated with disorders in gibberellic signal perception and transduction to GA-inducible genes. This group, unlike the first one, is characterized by a reduced response or insensitivity to GA.

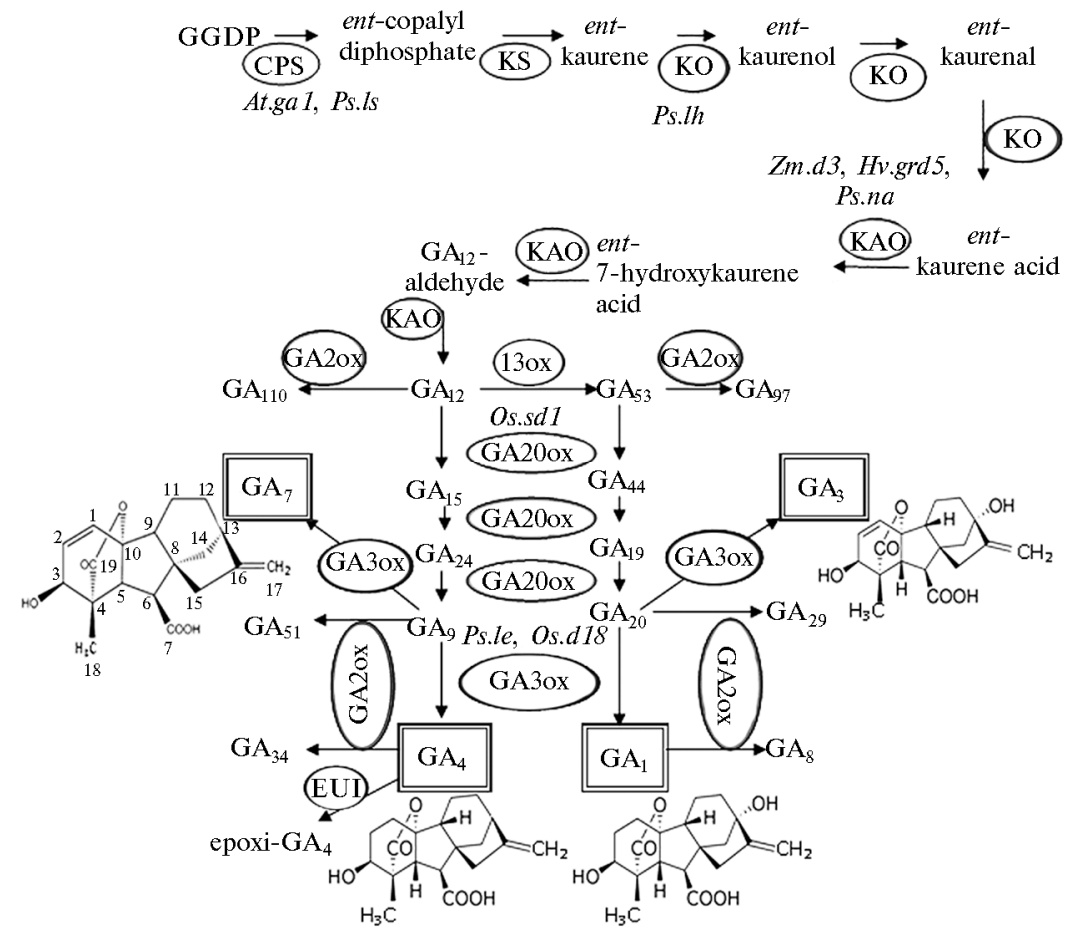

Fig. 1. Scheme of gibberellin biosynthesis [28] (as amended): GGDP - geranylgeraniol diphosphate, $\mathrm{GA}_{1-110}$ - gibberellins; CPS - ent-copalyl diphosphate synthase, KS - entkaurene synthase, KO - ent-kaurene oxidase, KAO - ent-kaurenoic acid oxidase; 13ox monooxygenase hydroxylating gibberellic $\mathrm{GA}_{12}$ aldehyde at $\mathrm{C} 13$ position; GA20ox, GA3ox and GA2ox - three groups of 2-oxoglutarate-dependent dioxygenases $\left(\mathrm{GA}_{20}\right.$-oxidase, $\mathrm{C} 3, \beta$-oxidase and C2, $\beta$-oxidase); EUI (Elongated Uppermost Internode) - GA deactivating epoxidase; At.gal, Ps.ls, Ps.lh, Zm.d3, Hv.grd5, Ps.na, Os.sd1, Ps.le, Os.d18 - dwarf mutants on relevant genes. Active gibberellins are marked with square frames; enzymes of gibberellin biosynthesis and deactivation are marked with ovals. 
Growth disorders due to mutations in the genes of GA biosynthetsis enzymes. All gibberellins derive from diterpene geranylgeraniol diphosphate (Fig. 1), which is also the precursor for carotenoids and unsaturated phytol, a diterpene alcohol forming part of chlorophyll. Gibberellin biosynthesis starts with the geranylgeraniol diphosphate cyclization occurring in the proplastid stroma [29, 30]. The final product of the cyclization is hydrophobic ent-kaurene. Its formation is catalyzed by ent-copalyl diphosphate synthase (CPS) and ent-kaurene synthase (KS). Arabidopsis plants with a knockout mutation in the gene encoding CPS (gal-3) are characterized by poor germination, dwarf type, underdeveloped root system, late flowering and male sterility [16, 29, 31-33]. Dwarf growth, flowering and seed formation disorders were also observed in pea, corn and rice mutants with knockout in CPS and KS genes, and also in the ent-kaurene oxidase (KO) and ent-kaurene acid oxidase (KAO) genes of the next phases of GA biosynthesis $[13,15,17]$. Treatment with gibberellin and its precursors restored normal plant phenotype, thus proving the important role of these enzymes in the biosynthesis of gibberellins.

The next stage of GA biosynthesis is a sequential oxidation of entkaurene to $\mathrm{GA}_{12}$ aldehyde with two monooxygenases from R450 cytochrome family (see Fig. 1), tht ent-kaurene oxidase (KO) and ent-kaurene acid oxidase (KAO) of CYP88A1 subfamily. In Arabidopsis, KO is localized on the outer surface of the outer plastid membrane, while KAO is associated with endoplasmic reticulum membranes [16, 19, 29]. Due to the mutations that lead to the loss of KAO activity, dwarf plants are observed in maize $d 3$ (dwarf3), barley grd5 (GAresponsive $d w a r f$ ) and na peas (nana) sensitive to GA [17-19]. Further reactions, beginning with $\mathrm{GA}_{12}$ aldehyde oxidation, occur in the cytoplasm and lead to the formation of various forms of gibberellins [28-30].

The production of active gibberellin forms involves soluble dioxygenases, using 2-oxoglutarate as a substrate. One group of these enzymes is $\mathrm{GA}_{20}$-oxidases (GA20ox), and the other group is the C3, $\beta$-oxidases (GA3ox, or C3, $\beta$-hydroxylases), of which the former oxidize $\mathrm{C}_{20}$-gibberellins to $\mathrm{C}_{19}$-gibberellins, and the latter catalyze hydroxylation of GA molecules at $\mathrm{C} 3, \beta$ position at the final stage of the biosynthetic pathway. Rice mutants with deactivated $G A 30 x$ and $G A 20$ genes were stunted [13, 34]. Semi-dwarf rice mutant sd1 (semi-dwarf1), used in the Green Revolution, carried the mutation in the GA20ox gene [13]. Along with the biosynthetic enzymes, the third group of dioxygenases called C2, $\beta$ oxidases (GA2ox) is also important in maintaining active gibberellins pool. These enzymes transform active GA and their precursors to inactive forms by hydroxylating the molecule at $C 2, \beta$ position $[29,35,36]$. In addition to $C 2, \beta$-oxidase, deactivation of gibberellins in rice plants may involve EUI epoxidase (Elongated Uppermost Internode phenotype) from the P450 monooxygenases family [28, 29], and in Arabidopsis methyltransferase (GAMT1 and GAMT2, Gibberellin Methyl Transferases 1, 2) may be involved [37]. Thus, the pool of active GA is sustained by various feedback mechanisms, which regulate expression of GA biosynthesis genes (GA20ox, GA3ox) and GA catabolism genes (GA2ox). Expression of these genes is specific regarding particular time and localization, and depends on lighting conditions, temperature and phytohormones [29]. The expression of genes involved in the final stages of GA biosynthesis is inversely correlated with bioactive GA level. As GA is accumulated, the $\mathrm{GA}_{20}$-oxidase gene expression is reduced, and GA catabolism gene expression is enhanced [38-40]. In the mutant dwarf pea plants (le) [21, 22] with a lack of GA due to reduced function of $\mathrm{C} 3, \beta$-oxidases the transcriptional activity of GA biosynthesis gene $(G A 20 o x)$ is high, while it is low for GA deactivation gene (GA2ox). In the pea mutants $S L N(S L E N D E R)$ with elongated shoots the disorders affect C2, $\beta$ - 
oxidase gene. In these plants due to suppressed GA deactivation the bioactive GAs are accumulated even despite a very small number of $\mathrm{GA}_{20}$-oxidase transcripts [23, 29].

GA reception and transmission of the signal. The currently accumulated data allow to suggest that GA signal reception and transmission events involve gibberellins receptor GID1 (Gibberellin Insensitive Dwarf 1); proteins with conserved DELLA motif, negative regulators of GA-signaling; SCF (SKP-Cullin-F-box) E3 ubiquitin-protein ligase covalently attaching ubiquitin to the target protein, and 26S proteasome; transcription factors (TF) with a DNAbinding domain; gibberellin-regulated genes.

In the early 1990s the existence of a GA receptor at the plasma membrane (PM) was hypothesized. The hypothesis that the binding of gibberellin molecules with PM receptor is a necessary step in GA-signal transduction was experimentally confirmed using aleurone cell protoplasts. For many years aleurone layer of grains has served as a convenient model for the study of GA signaling and responses [30]. During seed germination GA causes $\alpha$-amylase synthesis in the aleurone cells and secretion of this and other hydrolytic enzymes to endosperm for hydrolysis of stocked substances, which are subsequently used in the heterotrophic nutrition of the developing seedlings. In experiments, GA 4 linked covalently to sepharose granules induced $\alpha$-amylase gene expression in aleurone protoplasts with no cell walls. The size of the granules prevented GA molecules from penetrating into the cells, therefore, phytohormone reception had to occur on the cell surface [41]. Hypothetical gibberellin receptor on the aleurone cells PM was not found. Nevertheless, a GA signaling scheme involving this hypothetical receptor was proposed. It was designed by analogy with mechanism known for animal cells hormonal signal transduction from transmembrane receptor of GPCR-type (G-Protein-Coupled Receptor) to heterotrimeric Gprotein (GTPase, EC 3.6.5.1) [25]. The question whether the GPCR-type receptors in plants exist or not has not yet been resolved [42]. Currently, this role is attributed to several transmembrane proteins [27], while the G-proteins have been discovered, and their participation in the GA-signaling is indeed confirmed experimentally. Thus, the mutation in rice $d 1$ ( $d$ warfl) affects the gene encoding $\alpha$-subunit of the G-protein. Mutants in which Ga-protein activity could not be detected were stunted and characterized by attenuated responses to the GA [26]. However, the mechanism of participation of G $\alpha$-protein in GA signal transmission has not been conclusively determined [28, 43, 44]. It is known that G $\alpha-$ protein modulated physiological responses not only for GA-signaling but also for other hormones (brassinosteroids, abscisic acid - ABA) and environmental factors (blue light, ozone) [43].

GID1 gene (Gibberellin Insensitive Dwarf 1) was identified in rice dwarf mutants not responding to GA treatment [24]. It is believed to be the only GA receptor gene in rice [44]. Such a gene is also found in soybean and rape [45]. The relationship between the dwarf phenotype of plants and reduced GID1 gene expression in rape is allegedly caused by a mutation in the promoter region [46]. In the Arabidopsis genome three genes homologous to GID1 (AtGIDla, At$G I D 1 b$ and $A t G I D 1 s)$ are identified. Triple insertion mutant for these genes has a pronounced short form and is unable to reproduce [47].

Soluble GID1 protein is localized in the nucleus and in the cytoplasm [24, 48, 49]. Its C-terminal domain is highly homologous to plant carboxyl esterases of $\alpha$ - and $\beta$-hydrolase superfamily. However, GID1 is not esterase-active due to the substitution of key amino acid residues in the catalytic center [49]. In the GID1 there are HGG and GXSXG motifs conservative for carboxylesterase. The important role of GXSXG in GA reception is shown. The substitution of 
glycine residue $(\mathrm{G})$ with aspartate residue (D) in this motif leads to the development of GA-insensitive dwarf phenotype in rice gid1-1 mutants [50]. The possibility of GID1b association with the plasma membrane in Arabidopsis leaf tissue has been demonstrated recently [33], but the function of the protein with such localization has not yet been investigated.

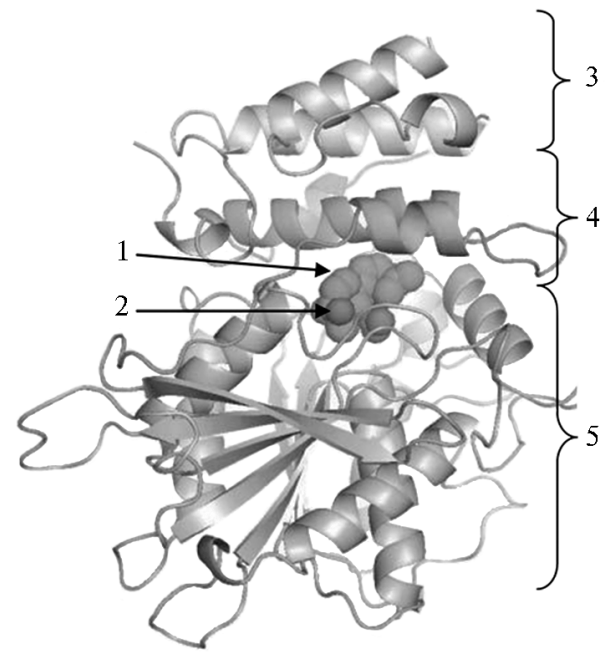

Fig. 2. The structure of HA-GID1-DELLA complex [51]: 1 - gibberellin molecule (GA), $2-$ polar groups of GA molecules, 3 - DELLA protein domain containing a conserved AspGlu-Leu-Leu-Ala sequence (DELLA), 4 - Nterminal «cap» domain of GID1 protein (Gibberellin Insensitive Dwarf 1), 5 - GID1 protein receptor pocket.

It is known that GID1 is composed of two domains different in size. The main part of the receptor $(\mathrm{C}$ terminal domain) forms a pocket (Fig. 2; 3, A) with the GA-binding site. The second small domain is located in the $\mathrm{N}$-end of the protein [51]. When interacting with GID1, the gibberellin molecule is directed with its nonpolar part into the pocket of the protein, and

the polar groups are bound to the receptor. In this, approximately 10 water molecules are also involved. Interaction with GID1 changes GA protein conformation so that $\mathrm{N}$-terminal domain like a lid shuts the receptor pocket. GID1 binds only the active gibberellins, and its affinity to $\mathrm{GA}_{4}$ is 20 times higher than to $\mathrm{GA}_{3}$. GA-GID1 complex is unstable (i.e., it quickly dissociates and then reassociates again) [50]. The affinity of this complex to DELLA-proteins is greatly increased. In turn, the interaction of the complex with DELLA significantly improves the stability of GID1-GA binding. It is shown that in the presence of DELLA protein the rate of dissociation of GA from GID1 decreases [50].

A

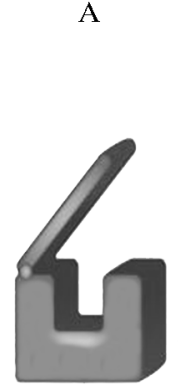

GID1

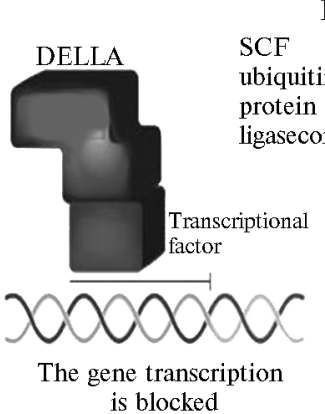

B

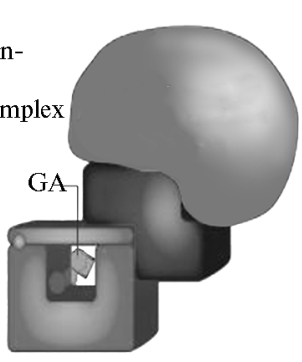

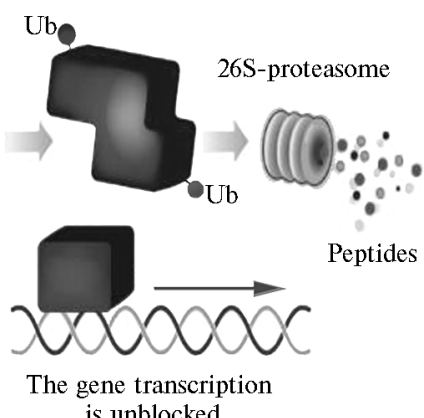

is unblocked

Fig. 3. Model of reception and transduction of gibberellin (GA) signal [52]: A - GID1 receptor (Gibberellin Insensitive Dwarf 1) is not bound with a gibberellin molecule; B - GA signal transduction resulting from interactions of a gibberellin molecule with GID1 receptor; DELLA - protein with a domain with Asp-Glu-Leu-Leu-Ala conserved sequence (DELLA), SCF - E3 ubiquitin protein ligase of the SCF Group (SKP, Cullin and F-box), Ub - ubiquitin tagging DELLA-protein.

When GA-GID1 interacts with DELLA-protein, a triple complex GAGID1-DELLA is formed. In this complex DELLA-protein with its N-terminal domain containing conserved sequences DELLA and TVHYNP binds with the GID1 lid protein. C-terminal domain of DELLA-protein, known as GRAS [53] interacts with the pocket GID1 protein fixing gibberellin molecule inside the complex [45]. GA-GID1-DELLA complex is recognized by E3 SCFSLY1/ GID2 
ubiquitin protein ligase [47] (see Fig. 3, B). In the recognition the important role is played by F-box domain-containing ligase subunit, the SLY1 (SLEEPY1) in Arabidopsis or GID2 (Gibberellin Insensitive Dwarf 2) in rice. These proteins of high affinity to the GA-GID1-DELLA complex induce interaction with ubiquitin protein ligase, which further leads to ubiquitination and subsequent degradation of DELLA-protein in $26 \mathrm{~S}$ proteasomes (see Fig. 3) [47 52, 54, 55]. Interestingly, as a prerequisite for ubiquitination of DELLA-protein serves its relationship with GID1 containing GA inside its receptor pocket. It is shown that DELLA can also bind GID1 without GA, but this does not increase its affinity to the F-box proteins of ubiquitin protein ligase [33, 56].

DELLA proteins suppress GA response because they reduce the expression of GA-dependent genes. Degradation of these proteins blocks their inhibitory effect, thereby triggering the expression of genes regulated by the GA [5658], the products of which are signals to the GA-induced plants growth and other GA-dependent responses, such as seed germination, flowering, etc. However, DELLA degradation is not always required to suppress its repressive functions. Proteolysis-independent DELLA inactivation is observed in the GAGID1-DELLA complex and at GID1 overexpression [40, 49, 59].

Proteins containing $\mathrm{F}$-box. In signal transduction pathway the GA induces degradation of DELLA repressor through interaction of GID1DELLA with E3 SCFSLY1/GID2 ubiquitin protein ligase complex. First the part of the ubiquitin ligase in the GA-signaling was found in Arabidopsis mutant sly1-10 and rice mutant gid2-1, having a dwarf phenotype, insensitive to GA treatment. These mutants were also noted for an unusually high content of DELLA proteins [54, 55, 60]. Genes SLY1 (Sleepy) and GID2 (Gibberellin Insensitive Dwarf 2) appeared to be positive regulators of GA signal. They encode proteins containing conserved F-box domain of about 60 amino acid residues, which is required for the interaction with DELLA and its subsequent degradation. Mutations that lead to loss of function of the repressive DELLA proteins partially restored growth in gid 2 and sly 1 plants, thus confirming the assumption that the dwarf type was caused by DELLA accumulation [54, 55].

SLY1 and GID2, containing F-box, form part of the E3 ubiquitin protein ligase complex of SCF-type, the main function of which lies in the electoral ubiquitin tagging proteins for subsequent degradation in the proteasome [60]. The name of SCF group is derived from the proteins that make up this sophisticated protein complex, i.e. SKR1 (S phase Kinase-associated Protein 1), CUL1 (Cullin) and a protein containing F-box domain [61]. The protein with F-box is responsible for target recognition. In Arabidopsis genome, 694 genes of proteins with this domain are identified. So proteins comprising F-box seem to form one of the largest protein families in plants [61].

SLY1 or GID2 proteins with their N-terminal part bind SKR1 through F-box, and with C-terminal domain comprising highly conservative GGF and LSL they bind the target DELLA protein [60]. In gid2 rice dwarf mutants there was a deletion in the region coding F-box domain, and in Arabidopsis sly1-2 and sly1-10 mutants SLY proteins was C-terminal end truncated. Because of the damage the proteins lost the ability to associate with DELLA-protein [54, 55].

Two GRAS sites of DELLA-protein are involved in interaction with Fbox protein domain, one of which has the conserved VHIID sequence, and the second comprises leucine repeated series (LR) [45, 56]. Thus, as the result of recognition by F-box protein of its target, a triple GID1-DELLA-SLY1 complex is formed. Interestingly, in mutants slyl-d due to the replacement of glutamic acid (E138) with lysine (K138) in GRAS domain the SLY acquired the ability to associate with the DELLA protein with its subsequent proteolysis regardless of 
the presence of the GA-GID1complex. These mutants were superior to dwarf plants in height [54].

Interaction between GA and other signaling pathways. Growth and development of the plants and their adaptation to external factors are under the control of plant hormones. Gibberellins are involved in many life processes of plants. However, in the absence of these hormones the development of stems, leaves and roots does not stop, but poor germinating and nonreproductive dwarf plants with altered sensitivity to external conditions are formed, indicating GA signal transduction to be a part of the complex signaling network, transmitting information from other external factors and hormones.

ABA (abscisic acid) and GA are antagonists, and each negatively regulates transcription of the other's biosynthetic genes. In addition, in case of promoters sensitive both to GA and ABA, the gene expression is influenced by these hormones oppositely [38]. It is known that auxin and GA stimulate growth of plant cells and tissues. These hormones have a positive effect on the biosynthesis of each other. Removal of the sprout apical buds, being the main source of auxin, caused a decrease in GA content in pea, poplar and tobacco [62]. Moreover, the interaction of signaling pathways of these hormones was identified so that auxin promoted GA-mediated DELLA degradation, and GA stimulated active polar auxin transport. In the study of poplar stem transcription profiles it was found that about $83 \%$ of the GA-regulated genes were also regulated by auxin. These include genes of transcriptional regulators of auxin (Aux/IAA, auxin/indolyl-3-acetic acid), GA (DELLA) and ethylene signaling (EIN3-like protein, Ethylene Insensitive 3), as well as genes which products regulate the cell wall elongation [62]. Interaction of the signaling pathways of cytokinin, auxin and gibberellin in the shoot apical meristem is well-studied [63]. Low-GA and high-cytokinin levels in apex maintained the proliferating cells undifferentiated. High accumulation of auxin and GA enabled cell differentiation and determined the location of leaf primordia. Interaction between GA, auxin and ethylene is shown on the example of the formation of hypocotylous hook from etiolated seedlings in Arabidopsis. Hypocotylous hook protects the apical meristem, helping to move seedling to the soil surface. It is formed due to asymmetric growth of the inner and outer sides of the hypocotyl. Ethylene and auxin control the hypocotyl bending via DELLA degradation. At the same time, ethylene induces retardation of root growth in Arabidopsis, reducing endogenous GA level by blocking biosynthesis gene, and increases the stability of DELLA proteins [64].

Thus, the active use of the dwarf forms of agricultural plants in breeding programs in 1940-1970s served as a powerful incentive for the research of genetic and physiological mechanisms of dwarf traits. Data accumulated over 30 years show that most of the known plant mutations associated with dwarf character are caused by disorders in metabolism or GA signaling pathways. However, changes in these processes at various stages may lead to opposite modifications of plant growth resulted in shortened or elongated stem. It is shown that the dwarfism in plants is associated with the lack of GA due to GA biosynthesis disorders or the accumulation of DELLA proteins, the repressors of GA-signaling, while giant plants are caused by an excess of gibberellins due to GA deactivation enzyme damage and(or) to the loss of the repressive function of DELLA proteins. Currently, this GA-induced suppression of repressive DELLA function seems to be the only characterized GA signal transduction pathway and explains well the role of gibberellins in hormonal regulation of plant growth. Nevertheless, probably, there are alternative GA signaling events, independent from DELLA proteolysis or incorporating G-protein, the role of which in the plant growth control has not yet been studied. Also, it remains unclear how the gib- 
berellins regulate the growth correlation between roots and stems. It is known that the roots are much more sensitive to GA than stems. The growth of the roots is activated by low GA concentrations insufficient to induce stem growth. Conversely, the GA concentration, being enough to activate stems tension, inhibits roots growth. It is believed that GAs are involved in plant shape control by adjusting stem to root growth rate [65].

In the breeding and genetic studies the response of dwarf forms to exogenous GA is traditionally used as evidence of their differences in the dwarf loci [66]. Understanding molecular mechanisms that determine intraspecific variability of plant height allows forecasting effective crossing and source material selection to create the varieties and interline hybrids with a desired phenotype. Particularly, for optimum adjustment of sunflower, breeding of which was mostly focused on high-yield heterosis hybrids, it is preferable to use dwarf lines as parents. In the VIR (N.I. Vavilov All-Russian Institute of Plant Genetic Resources) genetic collection of sunflower there are lines with dwarf traits determined by nonallelic genes and, therefore, controlled by different physiological and genetic mechanisms [67]. In-depth studies of these forms, along with the elucidation of the physiological and genetic causes of their uniqueness are necessary for effective breeding source material and cross breeding.

Thus, it has been shown that many low-growing varieties involved in the Green Revolution carried mutations in genes responsible for metabolism or transfer of gibberellin signal (GA). GA is involved in seed germination, growth of stems and roots. Changes in different GA-dependent processes can lead both to dwarf and giant plants. Of plant GAs well-known to date, the $\mathrm{GA}_{1}, \mathrm{GA}_{3}$, $\mathrm{GA}_{4}, \mathrm{GA}_{5}$ and $\mathrm{GA}_{7}$ are physiologically active. Their production involves $\mathrm{GA}_{20^{-}}$ oxidase and $C 3, \beta$-oxidase (or $C 3, \beta$-hydroxylase). $C 2, \beta$-oxidases are the main enzymes that can rapidly inactivate GA. Experimental data give reason to believe that in GA-signaling the GA induces degradation of DELLA repressor through GID1-DELLA interaction with E3 SCF ${ }^{\text {SLY1/GID2 }}$ ubiquitin protein ligase complex. Poor growth may be associated with a disorder in GA biosynthesis or accumulation of GA-signaling repressors (i.e., DELLA-proteins), while the high growth may be related to the damage of GA deactivating enzymes or the loss of a repressive function in DELLA proteins. Nowadays, GA-induced suppression of repressive DELLA function is known as the only characterized GA signal transduction pathway. Nevertheless, alternative GA-signaling pathways, which role has not been studied yet, can not be excluded. In-depth physiological and genetic studies of dwarf and tall plant forms are necessary for effective breeding.

\section{REFERENCES}

1. Kobylyanski i V.D. Rozh': Geneticheskie osnovy selektsii [Rye: The genetic basis of breeding]. Moscow, 1982.

2. Luk'y a n e n k o P.P., Z h og i n A.F. Selektsiya $i$ semenovodstvo, 1974, 1: 13-16.

3. Al'd e rov A.A. Genetika korotkostebel'nosti tetraploidnykh pshenits [Genetics of shortness in tatraploid wheat]. St. Petersburg, 2001.

4. B e s p a lov a L.A. V sbornike: Nauchnye trudy KNIISKH [In: Transactions of Krasnodar Research Institute of Agriculture]. Krasnodar, 1982: 103-120.

5. Yakushevski i V.S. V sbornike: Sorgo $v$ Yuzhnykh i Yugo-Vostochnykh raionakh SSSR [Sorghum in Southern and South-Eastern regions of the USSR]. Moscow, 1967: 19-36.

6. Kurkiev K.U., Kurkiev U.K., Al'd e rov A.A. Genetika, 2006, 42(3): 369-376 (doi: $10.1134 / \mathrm{S} 1022795406030082)$.

7. Z h d a n o v L.A. Doklady VASKHNIL, 1964, 6: 7-12.

8. Burmistrov L.A. V sbornike: Problemy otsenki iskhodnogo materiala $i$ podbora roditel'skikh par v selektsii plodovykh rastenii [The evaluation of original material and selection of parents in breeding fruit plants]. Michurinsk, 1996: 88-91.

9. Vavilov N.I. Zakon gomologicheskikh ryadov $v$ nasledstvennoi izmenchivosti [The law of 
homologous series in hereditary variability]. Moscow-Leningrad, 1935.

10. B orla g N.E. The impact of agricultural research on Mexican wheat production. Transactions of the New York Academy of Science, 1958, 20(3): 278-295 (doi: 10.1111/j.21640947.1958.tb00588.x).

11. K hu sh G.S. Green revolution: the way forward. Nat. Rev. Genet., 2001, 2(10): 815-822 (doi: 10.1038/35093585).

12. Ku ros a w E. Experimental studies on the nature of the substance secreted by the «bakanae» fungus. Trans. Nat. Hist. Soc. Formosa, 1926, 16: 213-227.

13. Sakamoto T., Miura K., I toh H., Tatsumi T., Ueguchi-Tanaka M., Ishiy a ma K., Kobayashi M., Agrawa 1 G.K., Takeda S., Abe K., Miyao A., Hirochika H., Kitano H., Ashikari M., Matsuoka M. An overview of gibberellin metabolism enzyme genes and their related mutants in rice. Plant Physiol., 2004, 134(4): 1642-1653 (doi: 10.1104/pp.103.033696).

14. Ji S.H., Gururani M.A., Le e J.W., Ahn B.-O., Chun S.-C. Isolation and characterization of a dwarf rice mutant exhibiting defective gibberellins biosynthesis. Plant Biol., 2014, 16(2): 428-439 (doi: 10.1111/plb.12069).

15. Phinney B.O., Spray C. Chemical genetics and the gibberellin pathway in Zea mays L. In: Plant Growth Substances 1982. P. Wareing (ed.). Academic Press, London, NY, 1982: 101-110.

16. Regnault T., Davie re J.-M., He intz D., Lange T., Achard P. The gibberellin biosynthetic genes AtKAO1 and AtKAO2 have overlapping roles throughout Arabidopsis development. Plant J., 2014, 80: 462-474 (doi: 10.1111/tpj. 12648).

17. D a vid son S.E., E 11 i o t t R.C., H e 11 i w e 11 C.A., P o o le A.T., Re id J.B. The pea gene NA encodes ent-kaurenoic acid oxidase. Plant Physiol., 2003, 131(1): 335-344 (doi: 10.1104/pp.012963).

18. Wi nkle r R.G., H e le n t jaris T. The maize Dwarf3 gene encodes a cytochrome P450-mediated early step in gibberellin biosynthesis. Plant Cell, 1995, 7(8): 1307-1317 (doi: 10.1105/tpc.7.8.1307).

19. Helliwe 11 C.A., Chandle r P.M., Poole A., Dennis E.S., Peacock W.J. The CYP88A cytochrome P450, ent-kaurenoic acid oxidase, catalyzes three steps of the gibberellin biosynthesis pathway. PNAS USA, 2001, 98(4): 2065-2070 (doi: 10.1073/pnas.98.4.2065).

20. Ayano M., Kani T., Kojima M., S akakibara H., Kitaoka T., Kuroha T., Ang e les-Shim R.B., Kit a no H., N a gai K., A shikari M. Gibberellin biosynthesis and signal transduction is essential for internode elongation in deepwater rice. Plant Cell Envir., 2014, 37: 2313-2324 (doi: 10.1111/pce.12377).

21. Reid J.B., Ross J.J. Mendel's genes: toward a full molecular characterization. Genetics, 2011, 189: 3-10 (doi: 10.1534/genetics.111.132118).

22. Reinecke D.M., Wickramarathna A.D., Ozga J.A., Ku re p i n L.V., Ji n A.L., G o od A.G., Pharis R.P. Gibberellin 3-oxidase gene expression patterns influence gibberellin biosynthesis, growth, and development in pea. Plant Physiol., 2013, 163: 929-945 (doi: 10.1104/pp.113.225987).

23. M a rti n D.N., P ro e b sting W.M., Hed d e n P. The SLENDER gene of pea encodes a gibberellin 2-oxidase. Plant Physiol., 1999, 121(3): 775-781 (doi: 10.1104/pp.121.3.775).

24. Ueguchi-Tanaka M., Ashikari M., Nakajima M., Itoh H., Katoh E., Kobayashi M., Chow T.Y., Hsing Y.I., Kitano H., Yamaguchi I., Mat s u o k a M. GIBBERELLIN INSENSITIVE DWARF1 encodes a soluble receptor for gibberellins. Nature, 2005, 437(7059): 693-698 (doi: 10.1038/nature04028).

25. Ha rtw e ck L.M., O $1 \mathrm{~s} z$ e w s k i N.E. Rice GIBBERELLIN INSENSITIVE DWARF1 is a gibberellin receptor that illuminates and raises questions about GA signaling. Plant Cell, 2006, 18(2): 278-282 (doi: 10.1105/tpc.105.039958).

26. Ueguchi-Tanaka M., Fujis awa Y., Kobay ashi M., Ashikari M., Iwasa ki Y., Kitano H., Mats u ok a M. Rice dwarf mutant $d 1$, which is defective in the subunit of the heterotrimeric $\mathrm{G}$ protein, affects gibberellin signal transduction. PNAS USA, 2000, 97(21): 11638-1643 (doi: 10.1073/pnas.97.21.11638).

27. Izawa Y., Takayanagi Y., Inaba N., Abe Y., Minami M., Fujisawa Y., Kato H., Ohki S., Kitano H., I was a k Y Y. Function and expression pattern of the subunit of the heterotrimeric G protein in rice. Plant Cell Physiol., 2010, 51: 271-281 (doi: $10.1093 / \mathrm{pcp} / \mathrm{pcp} 186)$.

28. $\mathrm{M}$ a Q., H e d d e n P., Z hang Q. Heterosis in rice seedlings: its relationship to gibberellin content and expression of gibberellins metabolism and signaling genes. Plant Physiol., 2011, 156(4): 1905-1920 (doi: 10.1104/pp.111.178046).

29. Hed d e n P., Thom as S.G. Gibberellin biosynthesis and its regulation. Biochem. J., 2012, 444: 11-25 (doi: 10.1042/BJ20120245).

30. M e d ved e v S.S., S h a r ov a E.I. Biologiya razvitiya rastenii. Tom 1. Nachala biologii razvitiya rastenii. Fitogormony [Biology of plant development. V. 1. Elements of plant development biology. Phytohormones]. St. Petersburg, 2011. 
31. Wils o n R.N., H e ckman J.W., S o me rville C.R. Gibberellin is required for flowering in Arabidopsis thaliana under short days. Plant Physiol., 1992, 100(1): 403-408 (doi: 10.1104/pp.100.1.403).

32. Tyler L., Thomas S.G., Hu J., Dill A., Alonso J.M., Ecker J.R., Sun T. DELLA proteins and gibberellin-regulated seed germination and floral development in Arabidopsis. Plant Physiol., 2004, 135(2): 1008-1019 (doi: 10.1104/pp.104.039578).

33. G a o X.-H., Xi a o S.-L., Ya o Q.-F., Wang Y.-J., Fu X.-D. An updated GA signaling «Relief of repression» regulatory model. Mol. Plant., 2011, 4(4): 601-606 (doi: 10.1093/mp/ssr046).

34. Sasaki A., Ashikari M., Ueguchi-Tanaka M., Itoh H., Nishimura A., Sw a pan D., I shiy a ma K., S a ito T., Kob ay a shi M., Khush G.S. Green revolution: a mutant gibberellin-synthesis gene in rice. Nature, 2002, 416(6882): 701-702 (doi: 10.1038/416701a).

35. Huang Y., Wang X., Ge S., R a o G.-Y. Divergence and adaptive evolution of the gibberellin oxidase genes in plants. BMC Evol. Biol., 2015, 15: 207 (doi: 10.1186/s12862-0150490-2).

36. Claeys H., D e B odt S., Inze D. Gibberellins and DELLAs: central nodes in growth regulatory networks. Trends in Plant Science, 2014, 19(4): 231-239 (doi: 10.1016/j.tplants.2013.10.001).

37. Varbanova M., Yamaguchi S., Yang Y., McKelvey K., Hanada A., Borochov R., Yu F., Jikumaru Y., Ross J., Cortes D., Ma C.J., Noel J.P., Mande r L., S hula ev V., Kamiya Y., Rodermel S., W e is s D., Pichersky E. Methylation of gibberellins by Arabidopsis GAMT1 and GAMT2. Plant Cell, 2007, 19(1): 32-45 (doi: 10.1105/tpc.106.044602).

38. Z e ntella R., Zhang Z.L., Park M., Thomas S.G., Endo A., Murase K., F l e e t C.M., J i k u m a r u Y., $\mathrm{N}$ a m b a r a E., K a m i y a Y., S u n T.P. Global analysis of DELLA direct targets in Arabidopsis. Plant Cell, 2007, 19(10): 3037-3057 (doi: 10.1105/tpc.107.054999).

39. We st o n D.E., E 11 i o tt R.C., Le st e r D.R., R a m e a u C., R e id J.B., Murfet I.C., Ros s J.J. The pea (Pisum sativum) DELLA proteins LA and CRY are important regulators of gibberellin synthesis and root growth. Plant Physiol., 2008, 147(1): 199-205 (doi: 10.1104/pp.108.115808).

40. Zhang Z.-L., O gawab M., F le et a C.M., Z e nte 11 a R., Hu a J., H e o c J.-O., Li m c J., K a mi y ab Y., Y a magu chib S., S u n T. SCARECROW-LIKE 3 promotes gibberellins signaling by antagonizing master growth repressor DELLA in Arabidopsis. PNAS USA, 2011, 108(5): 2160-2165 (doi: 10.1073/pnas.1012232108).

41. Hoole y R., B e a le M.H., S m i th S.J. Gibberellin perception at the plasma membrane of Avena fatua aleurone protoplasts. Planta, 1991, 183(2): 274-280 (doi: 10.1007/BF00197799).

42. Taddese B., Upton G.J.G., Bailey G.R., Jordan S.R.D., Abdulla N.Y., Reeves P.J., Reynolds C.A. Do plants contain G protein-coupled receptors? Plant Physiol., 2014, 164: 287-307 (doi: 10.1104/pp.113.228874).

43. Urano D., Che n J.-G., B ot e 11 a J.R., J o n e s A.M. Heterotrimeric G protein signaling in the plant kingdom. Open Biol., 2013, 3: 120186 (doi: 10.1098/rsob.120186).

44. Hed de n P., S p o n s e l V. Century of gibberellin research. J. Plant Growth Regul., 2015, 34: 740-760 (doi: 10.1007/s00344-015-9546-1).

45. Hirano K., Asano K., Tsuji H., Kawamura M., Mori H., Kitano H., Ueguchi-Tanaka M., Matsuoka M. Characterization of the molecular mechanism underlying gibberellin perception complex formation in rice. Plant Cell, 2010, 22(8): 2680-2696 (doi: 10.1105/tpc.110.075549).

46. Li H., Wang Y., Li X., G a o Y., Wang Z., Z ha o Y., W a ng M. A GA-insensitive dwarf mutant of Brassica napus L. correlated with mutation in pyrimidine box in the promoter of GID1. Mol. Biol. Rep., 2011, 38(1): 191-197 (doi: 10.1007/s11033-010-0094-2).

47. Griffiths J., Murase K., Rieu I., Zentella R., Zhang Z.L., Powers S.J., Gong F., Phillips A.L., Hed den P., Sun T.P., Tho m as S.G. Genetic characterization and functional analysis of the GID1 gibberellin receptors in Arabidopsis. Plant Cell, 2006, 18(12): 3399-3414 (doi: 10.1105/tpc.106.047415).

48. Nakaji ma M., Shimada A., Takashi Y., Ki m Y.C., Park S.H., U e guchiTanaka M., Suzuki H., Katoh E., I uchi S., Kobayashi M., Maeda T., M a t s u o k a M., Y a m a g c hi I. Identification and characterization of Arabidopsis gibberellin receptors. Plant J., 2006, 46(5): 880-889 (doi: 10.1111/j.1365-313X.2006.02748.x).

49. S u n T.-P. The molecular mechanism and evolution of the review GA-GID1-DELLA signaling module in plants. Cur. Biol., 2011, 21(9): R338-R345 (doi: 10.1016/j.cub.2011.02.036).

50. Ueguchi-Tanaka M., Nakajima M., Motoyuki A., Matsuoka M. Gibberellin receptor and its role in gibberellin signaling in plants. Annu. Rev. Plant Biol., 2007, 58(1): 183-198 (doi: 10.1146/annurev.arplant.58.032806.103830).

51. Murase K., Hirano Y., S un T.-P., Hakoshima T. Gibberellin induced DELLA recognition by the gibberellin receptor GID1. Nature, 2008, 456(7221): 459-463 (doi: 10.1038 /nature07519).

52. H id d e n P. Plant biology: gibberellins close the lid. Nature, 2008, 456(7221): 455-456 (doi: 
10.1038/456455a).

53. B o 11 e C. The role of GRAS proteins in plant signal transduction and development. Planta, 2004, 218: 683-692 (doi: 10.1007/s00425-004-1203-z).

54. Dill A., Tho m a s S.G., H u J., S t e be r C.M., S u n T.P. The Arabidopsis F-box protein SLEEPY1 targets gibberellin signaling repressors for gibberellin-induced degradation. Plant Cell, 2004, 16(6): 1392-1405 (doi: 10.1105/tpc.020958).

55. Sasaki A., Itoh H., Gomi K., Ueguchi-Tanaka M., Ishiyama K., Kobay a shi M., Je ong D.H., An G., Kitano H., Ashikari M., Matsuoka M. Accumulation of phosphorylated repressor for gibberellin signaling in an F-box mutant. Science, 2003, 299(5614): 1896-1898 (doi: 10.1126/science.1081077).

56. Hauvermale A.L., Ariizumi T., S teber C.M. Gibberellin signaling: A theme and variations on DELLA repression. Plant Physiol., 2012, 160: 83-92 (doi: 10.1104/pp.112.200956).

57. De Lucas M., Daviere J.-M., Rodriguez-Falcon M., Pontin M., Iglesias-Pedraz J.M., Lorrain S., Fankhause C., B lazquez M.A., Titarenko E., Prat S. A molecular framework for light and gibberellin control of cell elongation. Nature, 2008, 451(7177): 480-484 (doi: 10.1038/nature06520).

58. Feng S., Martinez C., Gusmaroli G., Wang Y., Zhou J., Wang F., Chen L.Y., Yu L., I g lesi as - Ped raz J.M., Ki r cher S., Schafer E., Fu X.D., F a n L.M., D e ng X.W. Coordinated regulation of Arabidopsis thaliana development by light and gibberellins. Nature, 2008, 451(7177): 475-479 (doi: 10.1038/nature06448).

59. Ari izu mi T., Murase K., S u n T.P., S t e be r C.M. Proteolysis-independent downregulation of DELLA repression in Arabidopsis by the gibberellin receptor GIBBERELLIN INSENSITIVE DWARF1. Plant Cell., 2008, 20(9): 2447-2459 (doi: 10.1105/tpc.108.058487).

60. M c Ginnis K.M., Thom as S.G., Soule J.D., Strader L.C., Zale J.M., Sun T., $\mathrm{S}$ te be r C.M. The Arabidopsis SLEEPY1 gene encodes a putative F-box subunit of an SCF E3 ubiquitin ligase. Plant Cell, 2003, 15(5): 1120-1130 (doi: 10.1105/tpc.010827).

61. Gagne J.M., Downes B.P., Shin-Han S., Durski A.M., Vierstra R.D. The Fbox subunit of the SCF E3 complex is encoded by a diverse superfamily of genes in Arabidopsis. PNAS USA, 2002, 99(17): 11519-11524 (doi: 10.1073/pnas.162339999).

62. Bjorklund S., Antti H., Uddestrand I., Moritz T., Sundberg B. Cross-talk between gibberellin and auxin in development of Populus wood: gibberellin stimulates polar auxin transport and has a common transcriptome with auxin. Plant J., 2007, 52(3): 499-511 (doi: 10.1111/j.1365-313X.2007.03250.x).

63. Hay A., Kaur H., Phillips A., Hedden P., Hake S., Tsiant is M. The gibberellin pathway mediates KNOTTED1-type homeobox function in plants with different body plans. Curr. Biol., 2002, 12(18): 1557-1565 (doi: 10.1016/S0960-9822(02)01125-9).

64. Achard P., Vriezen W.H., Van Der Straeten D., Harberd N.P. Ethylene regulates Arabidopsis development via the modulation of DELLA protein growth repressor function. Plant Cell, 2003, 15(12): 2816-2825 (doi: 10.1105/tpc.015685).

65. T a ni moto E. Tall or short? Slender or thick? A plant strategy for regulating elongation growth of roots by low concentrations of gibberellin. Ann. Bot., 2012, 110: 373-381 (doi: 10.1093/aob/mcs049).

66. Ce c coni F., Ga et ani M., Le nzi C., D u rant e M. The sunflower dwarf mutant dw1: effects of gibberellic acid treatment. Helia, 2002, 25(36): 161-166 (doi: 10.2298/HEL0236161C).

67. Gavrilova V.A., Rozhkova V.T., A n is i mova I.N. Sunflower genetic collection at the Vavilov Institute of Plant Industry. Helia, 2014, 37(60): 1-16 (doi: 10.1515/helia-2014-0001). 